\title{
Methods in modelling feeding behaviour and intake in herbivores
}

\author{
DR Mertens \\ US Dairy Forage Research Center, USDA-Agricultural Research Service, 1925 Linden Drive. \\ West, Madison, WI 53706 USA
}

\begin{abstract}
Summary - Intake of feed by animals is the result of interacting, but independent mechanisms of short, intermediate, and long-term feedback control. Long-term homeostatic regulation insures that the animal maintains a stable body energy state for its survival. For survival of the species, homeorhetic mechanisms insure a coordinated response of intake to the demands for growth, reproduction, and lactation. These mechanisms operate via nervous and hormonal controls to match intake with the present and future needs of the animal. Classical theories suggest that energy demand drives intake up to the limits imposed by gut fill. Metabolic comfort associated with the balance of absorbed nutrients or perhaps oxygen utilization efficiency may also provide an upper limit for intake. Long-term intake is the result of integration of multiple feedback signals that may be exclusive (the most limiting signal controls intake) or inclusive (signals interact in some way to jointly control intake). Daily or intermediate-term intake regulation appears to be less finely controlled than long-term intake. Fluctuations in daily intake may be responses to changes in body heat and metabolic nutrient pools from previous meals that serve to keep daily intakes near the long-term mean under homeostatic and homeorhetic control. Meal eating behaviour is the most variable of intake control mechanisms, which may reflect the sensitivity of the animal to external and gut-initiated stimuli that affect the initiation and cessation of meals. A conceptual model is described that illustrates the complex interactions inherent in a hierarchical system of feedback controls for intake.
\end{abstract}

\section{Introduction}

Nutritionists have sought for a long time a means of predicting ruminant productivity based on the nutritive value of feeds, the potential of the animal, and the characteristics of the environment in which the animal is fed. Numerous models (Monterio, 1972; Rice et al, 1974; Baldwin et al, 1977; Brown et al, 1977; Forbes, 1977a,b, 1983; Sanders and Cartwright, 1979; Mertens and Ely, 1979; Black, 1984; Bywater, 1984; Kahn and Spedding, 1984; Mertens, 1985, 1987; Loewer et al, 1986; Fisher et al, 1987; NRC, 1987; Williams et al, 1989; Danfaer, 1990; Hyer et al, 1991; Illius and Gordon, 1991; Tolkamp and Ketelaars, 1992; Sauvant, 1994; Ingvartsen, 1994; Finlayson et al, 1995) have been developed to predict animal responses based on simulations of current knowledge about animal digestive and metabolic processes. Approaches have ranged from empirical regression equations that describe responses for a specific set of conditions to mechanistic models that are based on theoretical cause- and-effect relationships with the aim of having universal applicability. However, production response models for ruminants still elude us because intake is not predicted reliably. Most current models of ruminant digestion and metabolism work best only when intake is a known input.

The importance of intake to models of animal response reflects the critical importance of intake to the survival of individual animals and their species. Ruminants are adaptive and self-regulating organisms that require feed as a source of nutrients and energy for maintenance, work, growth, reproduction, and lactation. If intake was not tightly regulated, we would observe animals that routinely starve for lack of food consumption or die from the stress of excessive weight. With a function so critical for survival, it seems logical that a complex system of regulation would evolve because any single simple system would leave the animal too susceptible to changes in its environment or physiological state that could result in nonsurvival. Thus, intake probably is regulated by complex mechanisms that control the 
initiation and cessation of feeding behaviour, the metabolism and expenditure of nutrients, and the stability of body weight in the animal.

From a systems analysis perspective, feed intake can be viewed as a self-regulating behaviour that results in body energy homeostasis in mature, non-productive animals. When changes in body energy associated with growth, fattening, reproduction, or lactation are taken into account, it is clear that intake regulation must also be closely coupled with homeorrhetic mechanisms (Bauman and Currie, 1980; Sauvant, 1994) that regulate the systematic changes in animal energy status or demand that are associated with each physiological state. Self-regulation implies some type of driving function with a feedback control mechanism. The control system for intake is not simple or direct because animals do not appear to have a mechanism for measuring energy and it is not metered as it is ingested (Brobeck, 1960). Nutrients simply are not absorbed fast enough after eating to be the signal that terminates meals. Adding to the complexity of intake regulation is the animal's ability to access tissue reserves and turnover pools to moderate any short term deficit in nutrient intake (Mogenson and Calaresu, 1978). Thus, it appears that intake regulation results from the integration of information from genetic programming, physiological status, tissue reserves and demands, gut signals, and the central nervous system. This information is transmitted by complex actions of both hormonal and nervous systems.

No single factor regulates intake under all circumstances; however, questions remain as to the identity of feedback systems and signals that affect intake, the method and level of integration of signals, and the decision process that controls feeding behaviour. Sauvant (1994) suggested that regulated systems can be divided into an operating subsystem and a regulating subsystem. This approach is useful in conceptualizing, discussing, and possibly in modelling the regulation of intake. Most models and research has focused attention on the operating subsystems (fill, energy absorption, etc.) with little development of the subsystem that integrates information from various signals and makes decisions that results in intake regulation.

The objective of this paper is to identify and discuss the essential elements needed in any regulating subsystem for simulating feeding behaviour and intake in ruminants. I will focus on the structure or architecture of the subsystem rather than the details of equations needed to describe or mimic a specific process. It is hoped that this structure can be a framework for a general submodel of intake regulation that would not only enhance our understanding and promote crucial research, but also become a robust predictor of intake. Accurate prediction of intake is the key to improving models of ruminant production so that intake is a response to feed, animal, and environmental characteristics rather than an external or empirical input. It is also the key to developing the next generation of systems for nutrient requirements and ration formulation that will focus on input/output response surfaces rather than "absolute" minimum requirements.

\section{Feedback control mechanisms}

Systematic review of intake patterns over short (meals within days), intermediate (among days), and long (months or years) periods, suggests that the fineness of regulation varies widely. Not only the fineness of regulation but also the mechanisms controlling the size of meals, intake among days, and long-term average intake may differ. Mayer (1968) proposed that intake regulation may be an interrelated hierarchy of feedback control mechanisms. I propose a general model of intake regulation in which within-day, amongday, and long-term feedback systems are interconnected to maintain a desired or defended body energy status (figure 1). In this approach, the intervals and sizes of meals within a day reflect the animal's attempt to adjust meals to compensate for discrepancies between previous meals and the animal's short-term demand for nutrients. Inaccuracies in intake regulation for one day are compensated by adjustments in intake on following days such that the animal achieves a desired body energy status over longer pericds of weeks, months and years. This suggests that short-and intermediate-term intake regulation results in oscillating behaviour that self-corrects around a central value that represents the long-term energy demand associated with homeostatic or homeorrhetic regulation of body energy status. 


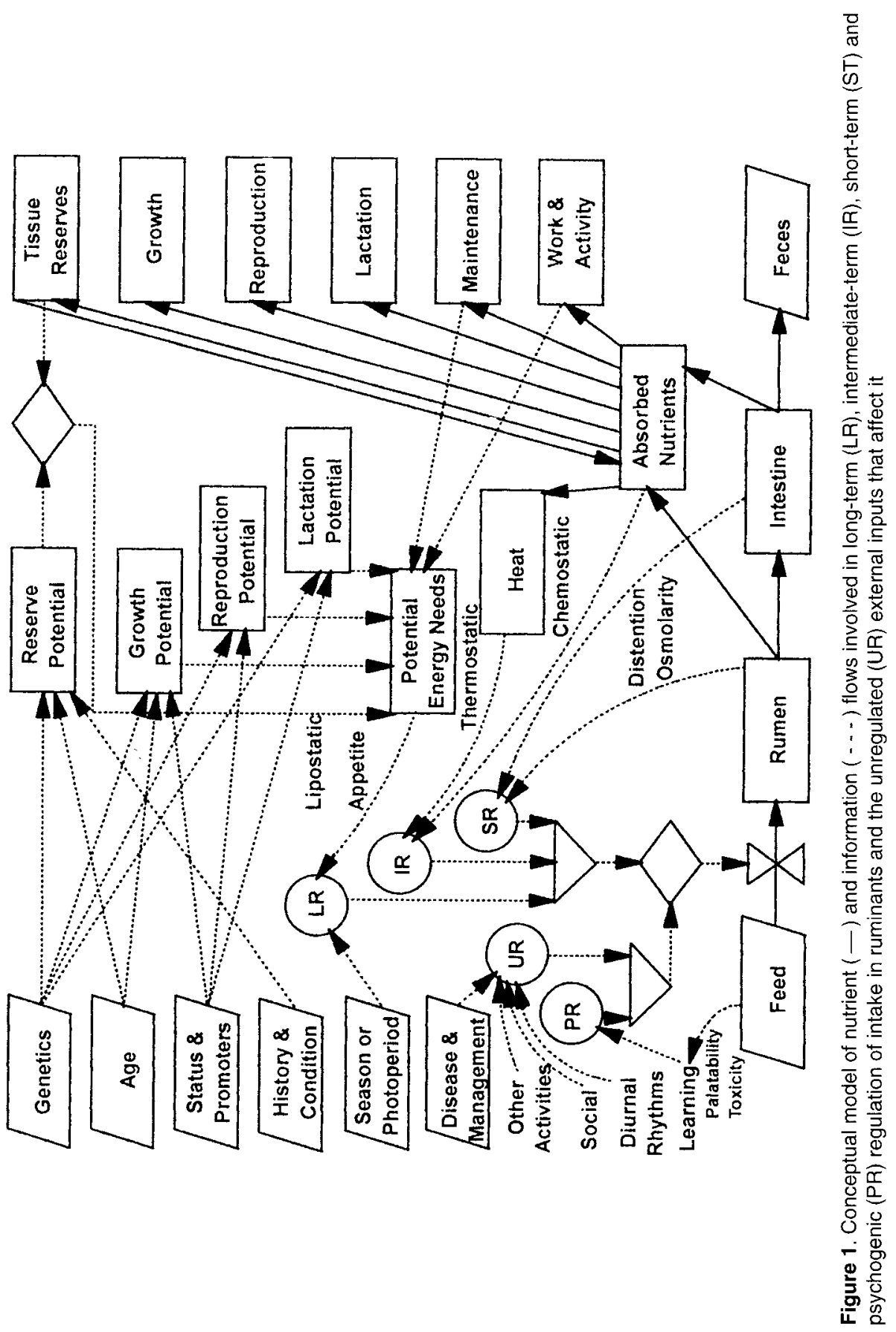


If this general model of intake regulation is valid, it raises questions about the complexity needed to model intake for specific uses. For example, if we are interested in predicting average intakes of groups of individual animals over weeks or longer, is it necessary to model the control of intake of individual meals within a day or variations among days? Can we aggregate these control mechanisms to simplify the model and achieve the robust predictions that are desired? How much of the fine structure of physiological information is needed to adequately predict the long-term intake that is the objective of most animal models? It is hoped that a general model of intake regulation will clarify the differences between long-term and short-term intake control, and eliminate some of the confusion between physiologists trying to identify the stimuli and receptors controlling feeding behaviour and nutritionists and modelers attempting to identify factors that allow the successful prediction of average intakes of animals in specific situations

\section{Long-term (months and years) regulation}

It appears that all models of intake regulation must contain some driving function that represents the intake demand over long periods of time. Appetite will be defined as this long-term drive to eat because it reflects the common use of the term when we indicate that an animal or person has a "good appetite." Variations in body size and physiological strategies for survival and reproduction among individuals, and especially among species and breeds, indicates that animals are genetically programmed for some level of body energy status. This genetic imprint may be viewed as a set point or potential to which the animal aspires. Although the concept of a set point may not be necessary to describe the equilibrium body energy status that is attained by animals in a dynamic situation, it nonetheless seems to be a concept with valid biological and control theory justification.

\section{Optimizing productivity versus efficiency}

Feedback control implies that some function is being optimized by achieving a maximal or minimal state. The key to successful modeling of regulated systems is the identification of the factor to be optimized. Classical intake regulation theories are based on the assumption that animals will maximize productivity and survival by maximizing food intake up to the limit of their genetic or physiological potential (Mertens, 1994). This theory implies that animals will strive for maximum energy intake until limited by fill or genetic potential. In the classical theory of intake regulation, the driving function for intake is the genetic potential for energy demand. According to this theory, it is variations in genetic programming among animals that result in different intakes and body energy status when they are provided the same diet.

It has been suggested that animals may regulate intake to optimize the efficiency of oxygen use by maximizing the amount of productive energy input per unit of oxygen consumed (Ketelaars and Tolkamp, 1992; Tolkamp and Ketelaars, 1992). However, without some type of genetic control, the theory of optimum efficiency would result in the same intake across species or breeds because, at the cellular level, biochemical pathways would lead to the same efficiency. It is clear that some type of driving function is needed to define the differences in characteristics of individuals, breeds, and species that influence long-term intake. Therefore, it appears that efficiency of oxygen use is not the driving function for intake, but more appropriately it is a feedback control mechanism analogous to fill or metabolic demand.

\section{Set points}

Genetically programmed control of body energy status implies some form of set point mechanism which requires: (1) a stimulus indicating current energy status, (2) a receptor for the stimulus, (3) a precise reference value for desired energy status, and (4) a mechanism for computing the difference between current and desired energy status (Booth et al, 1976). Although no physiological basis for a set point mechanism has been established, it seems possible for the genetic code of animals to contain this type of information. If not the true physiological mechanism, the set point concept may be useful in describing the outcome of intake regulation and in formulating mathematical models for simulating it. A dynamic system, especially one with feedback control processes, can achieve an equilibrium or steady-state that acts like a set-point 
because it tends to return to equilibrium after it has been perturbed. The difference between set points and dynamic equilibria is that the former is predefined, constant, and the driving function for the process; whereas the latter is variable and the result of a specific set of kinetic properties of the system.

Forbes (1977a) demonstrated that, if body rate was assumed to increase by $0.50 \mathrm{~kg} / \mathrm{d}$ and gut capacity was decreased 0.51 per $\mathrm{kg}$ increase in abdominal fat, cows will attain an equilibrium state of body weight and fatness without the need for a lipostat set point. Instead of a feedback mechanism based on a set point, stable weight was attained by a feedback mechanism in which intake was reduced as abdominal fat increased to the point where intake exactly balanced needs and no additional fattening occurred. This model does not prove that set points do not exist, only that alternative models can achieve the same endpoint. It is unclear whether genetic programming sets the endpoint boundaries or the rate coefficients that result in a stable equilibrium body weight. From a modeling perspective, either approach (set point or kinetic constants) can obtain identical results, but the control system is quite different. Variable body energy states, which depend on the characteristics of a dynamic system, are consistent with the "defended body weight" concept that Russek (1978) used to describe the variable weights that animals maintain in specific situations.

\footnotetext{
Homeostasis

Homeostasis of body energy is defined or limited by genetic potential and becomes the ultimate set point. Although dynamic systems may attain a steady-state or equilibrium point that appears to be the regulated or defended body energy status, this is not the same as a genetic potential or set point that the animal will achieve under ideal circumstances using homeostatic control. I contend that survival in the wild is dependent on having body energy reserves that can be drawn upon during times of food shortage. Because animals may not be able to anticipate food availability in the future, survival would be maximized by storing energy as body fat whenever food is abundant. Under this system, animals would maximize intake whenever possible until they achieve their ultimate capacity to store energy. This upper limit is probably defined genetically during
}

evolution by a balance between maximum energy stores and the locomotive force needed to move body mass during food gathering or when fleeing predators. Under homeostatic body energy regulation, the driving function for appetite would be the difference between the animal's current body energy status and the upper limit for body energy reserves established by genetics. This concept is compatible with the lipostatic theory of intake regulation. The physiological signals for this homeostatic system could be related to levels of some metabolite or fat soluble substance whose concentration in the blood is related to the size of fat depots. Homeostatic mechanisms function to maintain the animal in an optimal state for survival, and the maintenance energy requirement can be viewed as the energetic cost of this homeostatic state.

\section{Homeorhesis}

Four major factors tend to modify the long-term homeostatic equilibrium or set point status of animals during their lifetimes: age (growth and senescence), season, reproduction, and lactation. Because these events occur during periods of weeks, months, and years, the driving function for long-term appetite should reflect the coordinated neural, hormonal and physiological changes that influence the desired body energy status for each physiological state and situation. Using a new-born female animal as an example, a coordinated sequence of physiological events occur throughout her lifetime which define different energy states and demands. Initially, the animal is growing to attain its genetically programmed body size. The coordinated action of hormonal, neural, and metabolic activities results in a pattern of skeletal, muscle, digestive, and metabolically active tissue growth that is characteristic of the species. The potential rate of growth is a driving function for long-term appetite which appears to be augmented by any deficiency in intake that occurred in the past to limit growth. It is a common observation that when intakes have been restricted in the past and animals are below their genetically programmed weight at a given age they have an additional stimulus to eat, resulting in compensatory gain. At maturity, homeostatic mechanisms will assume control of intake resulting in a stable energy intake and body energy status under conditions of adequate feed quality and availability. 
Throughout the lifetime of the animal, intake is modified by environmental changes associated with season. It is not clear whether the signal for these changes is related to temperature or photoperiod. It also is not clear whether these changes are homeorhetic mechanisms that instinctively anticipate needs for each season or are dynamic equilibria associated with environmental differences among seasons.

Similar to growth, both pregnancy and lactation result in homeorhetic modification of the baseline homeostatic regulation of intake. During pregnancy, there is a tendency for females to store additional adipose reserves (in anticipation for the future demands of lactation after parturition?) which stimulate intake. This effect is counteracted in late pregnancy by reduced body capacity due to the growth of the foetus. During early lactation, the hormones which promote lactation also promote lipolysis from adipose tissues (Bauman and Currie, 1980). Thus, during early lactation, females typically deplete the body energy stored during pregnancy. It is critical that the effects of season and the age and physiological state of the animal be included in any model of intake regulation to account for the homeostatic and homeorhetic regulation of long-term intake.

\section{Intermediate-term (among days) regulation}

Daily intake appears to fluctuate around the long-term mean in such a way that days with below average intake are balanced by following days in which intake is above the mean. Poor correlations between energy intake and expenditure using daily balances (Edholm et al, 1955) indicate that daily energy intake is not regulated tightly. Body energy stores provide a buffer that accommodate intermediate and short-term deficits in energy intake. Several factors or signals can be envisioned that result in daily regulation of intake. Time required for rumination of meals consumed on previous days may result in lowered intake on following days if the ruminal load of long particle is large. Glucostatic, aminostatic, and thermostatic regulation are probably related to blood pools and total body heat load that is the average of conditions over intermediate periods of time. Thus, they could result in stimuli that adjusts current daily intake for past deviations from long-term appetite and for imbalances in absorbed nutrients that is associated with metabolic regulation of intake.

\section{Short-term (meals within days) regulation}

Although the need for energy by the body is continuous, meals are periodic. Intake varies widely within days ranging from zero intake when eating is not occurring to high rates of intake when fresh feed is presented or there has been a long interval since the last meal. The large variation in meal size and frequency suggests that intake control at this level is not finely regulated. Part of the variation in control is related to the fact that direct feedback based on absorbed nutrients from meals is not fast enough to terminate meals before overeating would occur. In addition to minimal direct feedback control, meal eating behaviour is affected by numerous psychogenic factors and factors, such as management and environment, that are not controlled by the animal.

\section{Physiological short-term control systems}

The major direct physiological feedback control mechanism for meal pattern is probably distension and fill. It is evident that a full rumen or stomach can provide the signal to terminate eating, especially when rations high in fibre and low in energy are fed (Balch and Campling, 1962; Campling, 1970; Bines, 1971). It is much less certain that distension would affect intake when high energy rations are fed. Nevertheless, it seems that distension should be one of the signals that is simulated in any model of intake regulation. Osmotic load also may be a signal for short-term regulation of feeding behaviour (Grovum, 1987). Recycling of sodium via saliva during rumination may play a role in the cyclic nature of meal patterns. Forbes (1995) suggested that sodium may attenuate nerve signals by its affect on action potentials. Thus, signals from distension receptors could be enhanced or augmented resulting in a rapid and sensitive feedback mechanism for meals.

\section{Psychogenic short-term control systems}

In addition to taste, smell, texture, and visual appeał; social interactions, emotional states, and learning can affect feeding behaviour. Mertens (1985) suggested that these characteristics be aggregated into a class of psychogenic modifiers of intake that relate to the animal's learning and behavioural responses to inhibitory and stimulatory factors in the feed or feeding environment which affect 
feeding behaviour. In this context, palatability is defined as a characteristic of feeds that is associated with gustatory, olfactory, or visual acceptability by animals. Compounds such as ammonia and protein degradation products are prime candidates for factors that affect the palatability of poorly fermented silages. Although palatability is a feed characteristic, it is in part the result of learned behaviour by the animal. It should be related to differences in intake that are not explained by differences in fill or nutrient availability of the feed. Related to palatability, but having a slightly different impact on intake is preference or selection. Preference or selection is a specific indication of palatability that is related to the relative acceptability of feeds or feed components when given a choice. Although it detects differences among feeds, preference may not affect intake when a single feed is offered (Black et al, 1989). Another learned behaviour that is related to palatability, but conceptually distinct, is food aversions associated with toxicity or ill health.

Intake is a conscious activity, therefore it is reasonable to conclude that other conscious activities may interact to affect feeding behaviour in ways that are not regulated by any feedback mechanism associated with physical or physiological signals. Social interactions among animals within a group may stimulate them to begin or end a meal. Likewise, interactions with man, such as the frequency, timing, and method of feeding or care and handling, can influence feeding behaviour. Diseases can also have an impact on the intake of animals. With the exception of disease, it is doubtful that most unregulated inputs which influence feeding behaviour would affect long-term intake. Because they are not related to either the operating or regulating subsystems of intake control, they can be effectively modeiled as stochastic processes. A possible exception to this assertion is that feeding management or strategies, such as the frequency and order of offering feeds in confinement systems, may affect digestion and passage and ultimately have an impact on physical and physiological mechanisms of intake regulation.

Allocation of time to various activities may be both a conscious and unconscious decision and is probably affected by physiological reflexes and psychogenic responses.
Nonetheless, time can be a constraint to feeding. If time of access to feed is limited artificially, intake will be affected. In an unrestricted natural setting, it is clear that animals cannot devote the entire 24 hours in a day to eating. In grazing situations, time is needed to gather in the feed and, if forage is sparse, the time needed to graze can limit intake. But Demment et al (1987) points out that time can limit intake even when forage is abundant because time is needed to ruminate previously ingested feed. Van Soest (1994) proposed that time for chewing activities may become an upper limit for intake in low quality, high fibre diets because time spent ruminating competes with eating time. It is unlikely that eating time has a fixed limit; rather, time is relegated to eating activity in response to nutrient demand and the time needed for ruminating, drinking, resting, and other activities. Implicit in the regulation of intake as a function of time availability is the distinction between day and night that influences the diurnal cycle of animal activities. Thus, any model of short-term feeding behaviour should include functions to mimic the diurnal activities of animals.

\section{Integration of feedback control systems}

It is clear that no single control mechanism regulates intake for all situations, but the method by which animals make the decision to eat is the greatest remaining mystery facing physiologists and modellers. It is unknown whether animals monitor instantaneous (differential) or cumulative (integrated over a period of time) signals to regulate intake. Instantaneous (or short term) changes in signals would provide rapid and direct regulation of intake. These feedback systems would be suitable, but not necessary for control of meal eating behaviour. Feedback systems based on instantaneous signals typically result in oscillating behaviour compared to those based on cumulative signals. Thus, feedback systems based on cumulative signals would provide a more stable system comparable to set point mechanisms. It is speculated that meal feeding behaviour may be related to instantaneous signals and long-term regulation may be based on cumulative signals. 


\section{Exclusive versus inclusive integration of feedback}

The method of integrating the signals for feedback control of long, intermediate, and short-term regulation of intake is uncertain. Integration of feedback signals by the animal can take one of two forms. Exclusive control indicates an either-or system of selecting the signal to control intake; whereas inclusive control means that signals are combined into a single stimulus. Most models (Rice et al, 1974; Forbes, 1977a,b; Sanders and Cartwright, 1979; Black, 1984; Bywater, 1984; Kahn and Spedding, 1984; Mertens, 1985, 1987; Williams et al, 1989; Danfaer, 1990; Hyer et al, 1991; Illius and Gordon, 1991; Finlayson et al, 1995) use some form of exclusive approach. The exclusive approach does not combine signals, but selects the most limiting factor to be the regulator of intake similar to "weak link" or «leaking barrel» concepts. The models of Rice et al (1974), Williams et al (1989), Danfaer (1990), Hyer et al (1991), and Illius and Gordon (1991) assume that intake is controlled only by ruminal fill to the exclusion of other factors. Other authors (Forbes, 1977a,b; Sanders and Cartwright, 1979; Kahn and Spedding, 1984; ) used an exclusive approach based on the physical or physiological limitations proposed by Conrad (1966) and Baumgardt (1970). Intake was the minimum of a physical limit based on faecal output or a physiological limit for digestible dry matter or energy intake (Conrad et al, 1964). Mertens (1985) added a third factor in his diagram of intake regulation, indicating that physical, physiological, or psychogenic mechanisms control distinct valves regulating inflow to the system. In his model, however, intake is defined as the minimum of intakes required to meet either the NDF intake constraint or that required to meet net energy demand, and psychogenic modulation of intake was assumed to be a multiplicative modifier of the intake that was limiting.

Poppi et al (1994) extended the exclusive approach to predict long-term intake using the most limiting of six factors. Intake was estimated using three physical (rate of intake, ruminal turnover, and faecal output) and three metabolic (genetic potential of protein deposition, heat dissipation, and ATP degradation via substrate cycling) limits and the minimum of these six was used to predict intake. For several diets, they observed that more than one mechanism of intake control became limiting simultaneously. In addition, ATP degradation was a limiting factor for most diets suggesting that the balance of nutrients that are absorbed has an important role in the regulation of intake. This mechanism illustrates the importance that imbalances in absorbed or metabolized nutrients may have on the intake regulation of high quality or protein-deficient forages (Egan, 1977; Weston, 1985; Owens et al, 1991). Poppi et al (1994) concluded that metabolic feedback may be a more encompassing mechanism for intake regulation than previously realized based on the model's predictions for seven diets.

The exclusive approach probably is too simple to reflect the actual mechanism in which animals appear to make compromises between the various control signals to arrive at a balance among productive output, body reserves, and intake. Forbes (1995) has suggested additivity of factors in the regulation of short-term feeding behaviour. Although the hypothalamus might integrate signals for hunger and satiety (Della-Ferra and Baile, 1984; Weston and Poppi, 1987), these concepts are difficult to represent mathematically. The integration of factors for longterm intake regulation appear to be even more difficult to describe both biologically and mathematically.

Fisher et al (1987) developed a model of intake regulation that integrates chemostatic and distension feedback controls using a multiplicative function. They calculated the ratio of optimum ruminal dry matter to current ruminal dry matter as a measure of distension and the ratio of optimal absolute rate of digestible dry matter absorbed to current absolute rate of digestible dry matter absorbed as a measure of the chemostatic effect. The chemostatic effect was modulated by an exponential function of distension and intake was then adjusted by the product of the distension and modulated chemostatic effects.

Sauvant et al (1996) developed an additive model in which eating behaviour is the difference between intake motivation (hunger) and satiety. Hunger is integrated as the product of feed palatability, the ratio between daily energy requirement and the previous days energy supply, and eating frequency differences between day and night. Satiety is the product of ruminal load and instantaneous energy balance. 


\section{Integrative primary signal}

The dilemma facing modellers of intake regulation is identifying the driving mechanism for feeding behaviour and intake. Is intake a "push" or "pull» function, e.g., is intake controlled directly and absorbed nutrients pushed through the metabolic system or is metabolic demand pulling nutrients through the system thereby creating a need that intake is regulated to achieve? Classical theories of intake regulation suggest the latter, that intake is a response to demand and not a primary input under direct control. The model illustrated in figure 1 indicates that the primary driving signal is based on a set point for potential energy needs which defines long-term appetite. The integration of feedback signals for controlling intake would involve the adjustment of this intake potential in relation to changes in body reserves and production.

The model described in figure 1 could also be developed without a set point by having the genetic potentials for body reserves, growth, reproduction, and lactation directly impact the fluxes of nutrients from the absorbed pool. If the size of the absorbed pool is a feedback control for intake fluxes, a dynamic system will arrive at an equilibrium that acts like a set point even if signals are modulated by the other factors that can limit intake, such as fill and palatability.

\section{Integrative systems}

Integration of feedback signals can be accomplished by exclusive or inclusive mechanisms described in section 2.1. In addition, feedback can be integrated by having the signal for one mechanism modify the set point or fluxes for other limiting mechanisms. Black (1984) described a feedback model in which three primary feedback mechanisms (energy demand, ruminal fill, and eating rate) are modified by other factors. The capacity of the animal to use energy was reduced when amino acid absorption was insufficient. Limits due to ruminal fill were modified by changing ruminal capacity in relation to body weight and potential metabolizable energy demand. The model of Finlayson et al (1995) also is based on physical and physiological feedback mechanisms in which the ruminal capacity limit is adjusted based on the ratio of the additional metabolizable energy requirement for reproduction to the metabolizable energy intake for normal productivity. Integration of signals by having feedback mechanisms influence one another seems to mimic the biological observation that ruminal fill increases in response to increased nutrient demand.

\section{Importance and operation of the meal feeding controller}

Although long-term intake is the cumulative result of meal eating behaviour, there is no consensus that control of feeding behaviour is directly related to regulation of long term intake. The situation is analogous to driving a car. The accelerator and brake control necessary short-term operations, but they are regulated by another system (the driver) that determines the average speed and destination that is chosen or attained. Modelling the shortterm actions of the accelerator and brakes will not result in a model that predicts the average speed on a specific trip no matter how detailed the model might be. Dividing feeding behaviour into a hierarchy of control mechanism helps to reinforce the concept of layered complexity of intake regulation and provides a rationale for aggregating mechanisms when intake is modelled at various levels. In practice, nutritionists are interested in average daily intake over the long term for predicting performance and formulating optimal rations. Because there is no consensus on how feeding behaviour impacts long-term average daily intake, only a brief discussion of the control of meal eating behaviour is provided.

The conceptual model in figure 1 suggests that meal initiation and cessation is the result of multiple inputs and regulating mechanisms. Changes in long-term appetite associated with potential energy needs for maintenance, activity, growth, reproduction, and lactation can increase or decrease the hunger stimulus for meals. Intermediate feedback representing the chemostatic and thermostatic balances from recent meals may simulate hunger or satiety signals depending on their size and frequency. Short-term regulation associated with distension and osmolarity probably function by affecting satiety signals that terminate meals. In addition, psychogenic modulation of intake via learned behaviour related to feeding management strategies and to feed palatability also influence feeding behaviour. Finally, there 
are external unregulated inputs related to day and night, social interactions, time constraints for other activities and disease which impact meal patterns. Thus, it is evident that accurate modelling of feed behaviour is and will be a complex process.

\section{Conclusions}

Regulation of intake is critical to the survival of animals and it appears that they have evolved a complex system of homeostatic and homeorhetic mechanisms for maintaining longterm body energy status. The mechanisms for long, intermediate and short-term feeding behaviour and intake may differ in the signals that are involved and the fineness of feedback regulation. Long-term intake is probably driven by the energy demand of the animal via various homeostatic and homeorhetic regulating subsystems. Multiple signals are integrated by some type of exclusive or inclusive mechanism to control intake. Exclusive integration indicates that only one of multiple signals limits intake. Inclusive integration means that the signals interact in a way in which they are combined, or the signal from one feedback mechanism impacts the signal of another mechanism in a way that affects its control over intake. Intermediate or daily intake may be related to metabolic nutrient pools and heat dissipation that result from previous daily intake activities. Short-term meal eating behaviour is most variable. This may be due to the sensitivity of short-term control mechanisms to instantaneous feedback signals, inputs of animal learning and behaviour, and unregulated stimuli associated with the feeding environment and interactions among animals and management. It appears that intake is under a hierarchical system of controls that regulate feeding behaviour, internal metabolic balances of nutrients, and coordinated changes in body energy status to insure the survival of the individual and its species.

\section{Literature cited}

Balch CC, Campling RC (1962) Regulation of voluntary intake in ruminants. Nutr Abstr Rev 32, 669-686.

Baldwin RL, Koong LJ, Llyatt MJ (1977) A dynamic model of ruminant digestion for evaluation of factors affecting nutritive value. Agric Systems 2, 255-288.

Baumgardt BR (1970) Control of feed intake in the regulation of energy balance. In: Physiology of digestion and metabolism in the ruminant ( AT Philipson, ed) Oriel Press Ltd, Newcastle upon Tyne, England, 235-253

Bauman DE, Currie WB (1980) Partitioning of nutrients during pregnancy and lactation: A review of mechanisms involving homeostasis and homeorhesis. J Dairy Sci63, 1514-1529.

Bines JA (1971) Metabolic and physical control of food intake in ruminants. Proc Nutr Soc 30, 116122.

Black JL (1984) The integration of data for prediction of feed intake, nutrient requirements and animal performance. In: Herbivore nutrition in the subtropics and tropics (FMC Gilchrist, RI Mackie, eds) Science Press, Craighall, South Africa, 648671

Black JL, Colebrook WF, Gherardi SG, Kennedy PA (1989) Diet selection and the effect of palatability on voluntary feed intake by sheep. In: Proc 50th Minnesota Nutr Conf, Bloomington, $M N$, September 18-20, Animal Sci Extension, Univ of Minnesota, St Paul, 139-151

Booth DA, Toates FM, Platt SV (1976) Control system for hunger and its implications in animals and man. In: Hunger: Basic mechanisms and clinical implications (D Novin, W Wyrwicka, GA Bray, eds) Raven Press, New York, 127-143

Brobeck JR (1960) Regulation of feeding and drinking. In: Handbook of physiology. Vol. II, Section 1, Neurophysiology (J Field, ed) Am Physiol Soc, Washington, DC, 1197-1206

Brown CA, Chandler PT, Holter JB (1977) Development of predictive equations for milk yield and dry matter intake in lactating cows. $J$ Dairy Sci 60, 1739-1754

Bywater AC (1984) A generalised model of feed intake and digestion in lactating cows. Agric Systems 13, 167-186.

Campling RC (1970) Physical regulation of voluntary intake. In: Physiology of digestion and metabolism in the ruminant (AT Philipson, ed) Oriel Press Ltd, Newcastle upon Tyne, England, 226-234

Conrad HR (1966) Symposium on factors influencing the voluntary intake of herbage by ruminants: Physiological and physical factors limiting intake. $J$ Anim Sci 25, 227-235

Conrad HR, Pratt AD, Hibbs JW (1964) Regulation of feed intake in dairy cows. I. Change in importance of physical and physiological factors with increasing digestibility. J Dairy Sci 47, 54-62

Danfaer A (1990) A dynamic model of nutrient digestion and metabolism in lactating dairy 
cows. Report 671, Nat Inst Anim Sci. Foulum, Denmark, 511

Della-Fera MA, Baile CA (1984) Control of teed intake in sheep. J Anim Sci 59, 1362-1368

Demment MW, Laca EA, Greenwood GB (1987) Intake in grazing ruminants: A conceptual framework. In: Proc Symp on Feed intake by beef cattle ( $F$ Owens, ed) Report MP-121, Oklahoma State Univ Agric Expt Sta, Stillwater, 208-225

Edholm OG, Fletcher JG, Widdowson EM, McCance RA (1955) The energy expenditure and food intake of individual men. Br J Nutr 9, 286-300

Egan AR (1977) Nutritional status and intake regulation in sheep. VIII. Relationships between the voluntary intake of herbage by sheep and the protein:energy ratio in the digestion products. Aust J Agric Res 28, 907-915

Finlayson JD, Cacho OJ, Bywater AC (1995) A simulation model of grazing sheep: I. Animal growth and intake. Agric Systems 48, 1-25

Fisher DS, Burns JC, Pond JC (1987) Modelling ad libitum dry matter intake by ruminants as regulated by distension and chemostatic feedbacks. J Theor Biol 126, 407-418

Forbes JM (1977a) Interrelationships between physical and metabolic control of voluntary food intake in fattening, pregnant and lactating mature sheep: A model. Anim Prod 24, 91-101

Forbes JM (1977b) Development of a model of voluntary food intake and energy balance in lactating cows. Anim Prod 24, 203-214

Forbes JM (1983) Models for the prediction of food intake and energy balance in dairy cows. Livest Prod Sci 10, 149-157

Forbes JM (1995) Voluntary food intake and diet selection in farm animals. CAB International, Oxon, UK, $532 \mathrm{p}$

Grovum WI (1987) A new look at what is controlling food intake. In: Proc Symp on Feed intake by beef cattle (FN Owens, ed) Report MP-121 Oklahoma State Univ Agric Expt Sta, Stillwater, $1-39$

Hyer JC, Oltjen JW, Galyean ML (1991) Development of a model to predict forage intake by grazing cattle. J Dairy Sci 69, 827-835

Illius AW, Gordon IJ (1991) Prediction of intake and digestion in ruminants by a model of rumen kinetics integrating animal size and plant characteristics. J Agric Sci, Camb 116, 145-157

Ingvartsen KL (1994) Models of voluntary food intake in cattle. Livest Prod Sci 39, 19-38

Kahn HE, Spedding CRW (1984) A dynamic model for the simulation of cattle herd production systems: 2 - An investigation of various factors influencing the voluntary intake of dry matter and the use of the model in their validation. Agric Systems 13, 63-82.

Ketelaars JJMH, Tolkamp BJ (1992) Toward a new theory of feed intake regulation in ruminants. 3 . Optimum feed intake: In search of a physiological background. Livest Prod Sci 31, 235-258

Loewer OJ, Smith EM (1986) The Kentucky beefforage model. In: Simulation of beef cattle production systems and its use in economic analysis (TH Spreen, DH Laughlin, ed) Westview Press, Inc Boulder, CO, 63-100

Mayer J (1968) Overweight causes, cost and control. Prentice-Hall, Englewood Cliffs, NJ

Mertens DR (1985) Factors influencing feed intake in lactating cows: From theory to application using neutral detergent fiber. Proc Georgia Nutr Conf 1 18

Mertens DR (1987) Predicting intake and digestibility using mathematical models of ruminal function. $J$ Anim Sci 64, 1548-1558.

Mertens DR (1994) Regulation of forage intake. In: Forage quality, evaluation, and utilization (GC Fahey Jr, ed) Am Soc Agron, Madison, WI, 450493

Mertens DR, Ely LO (1979) A dynamic model of fiber digestion and passage in the ruminant for evaluating forage quality. J Anim Sci 49, 1085-1095

Mogenson GJ, Calaresu FR (1978) Food intake considered from the viewpoint of systems analysis. In: Hunger models. Computable theory of feeding control (DA Booth, ed) Academic Press, New York, 1-24

Monterio LA (1972) The control of appetite in lactating cows. Anim Prod 14, 263-281

National Research Council (1987) Predicting feed intake of food-producing animals, National Academy Press, Washington, DC, $85 p$

Owens FN, Garza J, Dubeski P (1991) Advances in amino acid and $\mathrm{N}$ nutrition in grazing ruminants. In: Proc 2nd Grazing Livestock Nutr Conf, Report MP-133 Oklahoma Agric Exp Stat, Oklahoma State Univ., Stillwater, 109-137

Poppi DP, Gill M, France J (1994) Integration of theories of intake regulation in growing ruminants. J Theor Biol 167, 129-145

Russek M (1978) Semi-quantitative simulation of food intake control and weight regulation. In: Hunger models. Computable theory of feeding control (DA Booth, ed) Academic Press, New York, 195-226

Rice RW, Morris JG, Maeda BT, Baldwin RL (1974) Simulation of animal functions in models of production systems: Ruminants on the range. Fed Proc 33, 188-195

Sanders JO, Cartwright TC (1979) A general cattle production systems model. Part 2. Procedures 
used for simulating animal performance. Agric Systems 4, 289-309

Sauvant D (1994) Modelling homeostatic and homeorhetic regulation in lactating animal. Livest Prod Sci 39, 105-113.

Sauvant D, Baumont R, Faverdin P (1996) Development of a mechanistic model of intake and chewing activities of ruminants. J Anim Sci (in press).

Tolkamp BJ, Ketelaars JJMH (1992) Toward a new theory of feed intake regulation in ruminants. 2 . Costs and benefits of feed consumption: An optimization approach. Livest Prod Sci 30 , 297-317
Van Soest PJ (1994) Nutritional ecology of the ruminant. Second edition. Cornell Univ Press, Ithaca, NY, $476 \mathrm{p}$

Weston RH (1985) The regulation of feed intake in herbage-fed ruminants. Proc Nutr Soc Aust 10, 55-62.

Weston RH, Poppi DP (1987) Comparative aspects of food intake In: The nutrition of herbivores (JB Hacker, JH Ternouth, eds) Academic Press, Sydney, 133-162

Williams CB, Oltenacu PA, Sniffen PA (1989) Application of neutral detergent fiber in modeling feed intake, lactation response, and body weight changes in dairy cattle. J Dairy Sci $72,652-663$ 